\title{
Oskar Negt
}

\section{Joachim Perels zum 70. Geburtstag}

Zum 70. Geburtstag eines Freundes und politischen Weggefährten möchte man in der Gratulation gerne einige Charakterzüge unterbringen, die etwas quer stehen zum offiziellen Bild des Geehrten. Ich kenne Joachim Perels schon über 40 Jahre; bei der Suche nach Material für diesen Geburtstagsgruß sind mir Teilnehmerlisten meiner Frankfurter Kantseminare in die Hände gefallen, in die sich Perels (mit präzisen Angeboten für Seminararbeiten) regelmäßig eingetragen hat. Obwohl ich ihn also so lange kenne, haben sich mir Facetten seiner Persönlichkeit und seiner Denkweise erst erschlossen, als ich, aus gegebenem Anlass, seine Schriften noch einmal, jetzt unter lebensgeschichtlicher Blickrichtung las. Es ist ja Vorsicht geboten, wenn die Wahrheitsgehalte wissenschaftlicher Arbeit in einen biografischen Zusammenhang gerückt und Kausalverhältnisse hergestellt werden, die eindeutige Abhängigkeiten nahelegen.

Es ist jedoch auffällig, dass der Grundton in den Schriften von Perels durch Aufarbeitung und geschichtliche Erinnerung bestimmt wird. Das ist in dieser Nachdrücklichkeit sonst nur bei Menschen der Fall, die sich schuldig fühlen, weil sie die Hölle überlebt haben. Beispielhaft dafür sind Ralph Giordano’s „Erinnerungen eines Davongekommenen“. Die Wundmale solcher Menschen hören nicht auf zu schmerzen, und sie drängen darauf, auch das Leiden anderer „beredt zu machen", wie Adorno das ausdrückt.

Aber Joachim Perels ist kein Davongekommener, kein Überlebender im Sinne Giordanos. Er ist 1942 geboren, Kriegskind, mit allen Schreckerfahrungen damaliger Kindheit. Gleichwohl scheint er in seiner Gefühlswelt in einer Weise sein wissenschaftliches und politisches Leben den Opfern der Geschichte gewidmet zu haben, wie das in der akademischen Welt nur selten anzutreffen ist. Es ist nun für seine Denkweise charakteristisch, dass seine wichtigsten Texte den Geist der Dankbarkeit des Überlebens und der Trauer über die Opfer atmen; aber die Opfer, die Ausgegrenzten, die Marginalisierten, die Vertriebenen sind nie bloß geschichtliche Verlierer. Vielmehr sind es Hoffnungsträger, vielfach auch Sinnstifter. Diese enge Verknüpfung von Opfer und Sinn, die ich in den Schriften sowohl des Politikwissenschaftlers als auch des Juristen Joachim Perels wahrnehme, kann freilich nur gelingen, wenn die Gesellschaftsanalysen mit einem Schuss religiösmessianischen Bewusstseins versetzt sind.

Vielleicht liegt die Kraftquelle dieses überschüssigen Bewusstseins in der Familientradition, einer Art geistiger Erbschaft. Denn seit Generationen verteilen sich die Karrieren der Perels-Familie auf Rechtswissenschaft und Theologie. Deren Glaubenswelt besteht aus einem weltoffenen, dem Wohl und Wehe des Gemeinwesens verpflichteten Protestantismus; das gilt insbesondere für Justus Perels, den hochangesehen kirchlichen Rechtsberater, der seinem Sohn gleichsam den kategorischen Imperativ einpflanzte, alles zu tun, damit Auschwitz sich nicht wiederhole.

Es ist nun bemerkenswert, dass in der Lebenswelt von Joachim Perels zwei mit höchster Achtung bedachte Persönlichkeiten verschmelzen: Justus Perels und Dietrich Bonhoeffer. Man mag hier von idealisierten Vaterfiguren sprechen. Sie sind Freunde in ihrer kirchlichen Berufswelt; sie sind Teilnehmer am Widerstand, wurden beide (aus politischen Gründen) zum Tode verurteilt und beide kurz vor dem Ende der Naziherrschaftermordet. 
Joachim Perels, der die große Bedeutung der von Korsch geforderten „Juristischen Aktion“ sehr wohl einzuschätzen weiß, beharrt trotzdem auf dem messianischen Blick; in einem seiner überzeugendsten Essays („Judentum und Gesellschaftskritik. Zu Motiven in Adornos Denken“) schreibt er: „Der Messianismus ist ein normativer Fluchtpunkt, der, obwohl die Wirklichkeit nicht zum Gedanken drängt, das historische Ziel einer humanen Welt in großen Erwartungsgebilden festhält.“ Und er zitiert Adorno: „Erkenntnis hat kein Licht, als das von der Erlösung her aus der Welt scheint: alles andere ... bleibt ein Stück Technik."

Als ich meinen 70. Geburtstag feierte, überreichte mir Joachim Perels ein Buch mit der Bemerkung: Es ist mir schwer gefallen, mich von ihm zu trennen! Ich war gespannt; ich blätterte, fand auf der ersten Seite den Namen der Besitzerin: Helga Perels und eine handschriftliche Widmung, die mir galt: Das Buch enthielt Dietrich Bonhoeffers „Briefe und Aufzeichnungen aus der Haft, Widerstand und Ergebung." Warum Bonhoeffer? wagte ich zu fragen. Joachim antwortete: Lies die Widmung. Da stand: „Es ist die Erstausgabe des in der Haft entstandenen Buchs von Dietrich Bonhoeffer, dem Du (wie meinem Vater) in Deiner Abschiedsvorlesung über Kant und Marx Reverenz erweist. Das revolutionäre Buch, das meiner Mutter gehörte, enthält den urchristlichen Gedanken einer antiklerikalen Weltlichkeit, der das soziale Leben von Grund auf verändert. Es passt, denke ich, zum Vorrat kritischer Erkenntnisse, die Du bis heute lebendig hältst".

Ein revolutionäres Buch nennt Perels diese Aufzeichnungen Bonhoeffers; diese Zuordnung überrascht: Denn im Text geht es um eine radikale Umdefinition eines an der Aufklärungstradition orientierten Fortschrittsbegriffs; Bonhoeffer stellt hier in Zweifel die Gültigkeit einer „westlichen Aufklärung“, die mit dem griechisch-römischen Erbe arbeitet und für die in der Neuzeit die Renaissance steht; er rehabilitiert die mittelalterliche Poesie, Parzival, Magdeburger und Naumburger Dom, die ihm zufolge nachdrücklicher als die Klassikbezüge humanistische Grundbegriffe, wie Menschlichkeit, Toleranz, Milde, Maß, ausdrücken.

Was Joachim Perels an Bonhoeffers (und wohl auch seines Vaters) Option für ein christliches, aber antiklerikales Weltverständnis so fasziniert, ist offenbar die damit verknüpfte Haltung, die Bonhoeffer in seinen Gefängnisbriefen als „Hilaritas" beschreibt. Im lateinischen Ursprungssinne bezeichnet das Frohsinn, Heiterkeit (im Unterschied zu tristitia), im Bonhoefferschen Verständnis ist damit ein Grundvertrauen zur Welt gemeint, das die Basis für die Wertschätzung des eigenen Werks ist. Hilaritas ist, wie Bonhoeffer sagt, „die Zuversicht zum eigenen Werk, als Kühnheit und Herausforderung der Welt ... als feste Gewissheit, der Welt mit dem eigenen Werk, auch wenn es ihr nicht gefällt, etwas Gutes zu erweisen ..."

Seine Hilaritas ist gewiss eine Utopie; aber es ist schon eindrucksvoll, wenn ein Mensch, der unter fortwährenden Todesdrohungen steht, eine solche Lebensmaxime formuliert, die sich für Perels mit urchristlichen Motiven der Welteinstellung verknüpft. So ist dem streitbaren Intellektuellen und dem gelehrten Bibelkenner, anlässlich seines 70. Geburtstag der Wunsch auf den Weg zu geben, in seinem Kampf für die Mühseligen und Beladenen, für die Beleidigten und Erniedrigten etwas mehr von der Bonhoefferschen Hilaritas anzunehmen. 